Original Article

\title{
NOVEL UV SPECTROPHOTOMETRIC METHOD FOR THE DETERMINATION OF TERIFLUNOMIDE IN TABLET DOSAGE FORM
}

\author{
VISHWAS T. S., GURUPADAYYA B. M.* \\ Department of Pharmaceutical Chemistry, JSS College of Pharmacy, JSS Academy of Higher Education and Research, Mysuru 570015, India \\ Email: bmgurupadayya@jssuni.edu.in
}

Received: 15 May 2019, Revised and Accepted: 17 Jul 2019

\section{ABSTRACT}

Objective: The current work is intended towards the development of a novel, simple, and precise UV spectrophotometric method for the estimation of teriflunomide (TEF) present in the marketed formulation.

Methods: Acetonitrile was used as asolvent and the absorbance of the drug was measured at the absorbance maxima of TEF, UV $284 \mathrm{~nm}$.

Results: Calibration curve plotted in concentration range 5-10 $\mu \mathrm{g} / \mathrm{ml}$ exhibited excellent linear relationship with line equation $\mathrm{y}=0.0858 \mathrm{x}-0.0223$ and $\mathrm{r}^{2}$ value of 0.9996 . The method was found to comply all the validation parameters as per the ICH guideline indicating the sensitivity of the method towards analyte.

Conclusion: The method can be used satisfactorily for the routine analysis of TEF present in marketed formulation.

Keywords: UV spectrophotometric, Teriflunomide, Marketed formulation, ICH guideline, Sensitivity

(C) 2019 The Authors. Published by Innovare Academic Sciences Pvt Ltd. This is an open-access article under the CC BY license (http://creativecommons.org/licenses/by/4.0/) DOI: http://dx.doi.org/10.22159/ijcpr.2019v11i5.35711

\section{INTRODUCTION}

Teriflunomide (fig. 1) is an orally administered, second-generation immunosuppressive/immunomodulatory agent which is an active metabolite of Leflunomide. It acts by competitively inhibiting dihydroorotate dehydrogenase, an enzyme which is responsible for pyrimidine de novo bio-synthesis [1-4].

Literature survey disclosed some chromatographic methods such as HPLC [5-8], LC-MS [9-12] for the quantitative estimation of TEF present in API, marketed formulation and biological fluids.

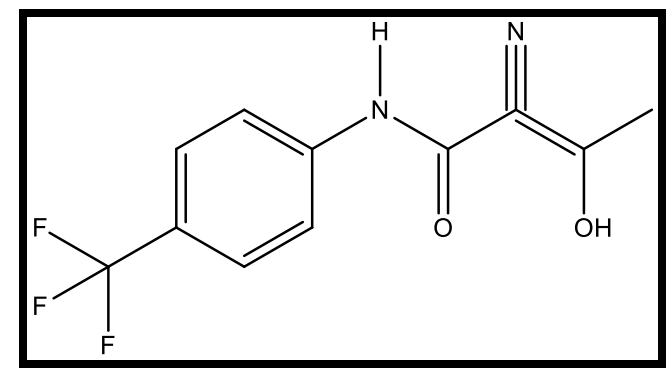

Fig. 1: Teriflunomide

No UV spectrophotometric method has been reported so far, for the estimation of TEF in marketed formulation. Therefore, the current work is directed towards the development of a novel UV spectrophotometric method for the estimation of TEF in marketed formulation and its validation according to ICH guidelines [13,14].

\section{MATERIALS AND METHODS}

\section{Materials and reagents}

Teriflunomide pure drug (API) was procured as a gift sample from Glenmark Ltd., Noida. All the other reagents used were of analytical grade and were procured from specialties private limited, Mumbai, India. Marketed Formulation (Denopsy 14 tablets) was purchased from a local pharmacy shop.

\section{UV instrumentation}

Shimadzu UV-1800, a double-beam UV-Visible spectrophotometer along with $1 \mathrm{~cm}$ identical quartz cuvettes was used to measure the absorbance. UV Probe PC software was used to control the instrument and to analyze the data obtained.

\section{Preparation of standard solution}

Stock solution comprising $100 \mu \mathrm{g} / \mathrm{ml}$ of TEF was prepared by using acetonitrile as a diluent. $0.5,0.6,0.7,0.8,0.9$ and $1 \mathrm{ml}$ of this solution was pipetted out in five different $10 \mathrm{ml}$ volumetric flask and the volume was made up, to get a working solution consisting of $5,6,7,8,9$ and $10 \mu \mathrm{g} / \mathrm{ml}$.

\section{Preparation of sample solution (Formulation)}

As specified in the label, each tablet contains $14 \mathrm{mg}$ of TEF. Weight of 10 tablets was noted and crushed using mortar and pestle, the quantity of powder corresponding to $10 \mathrm{mg}$ of teriflunomide was taken in a $10 \mathrm{ml}$ volumetric flask and the volume was made up with acetonitrile. Required dilutions were made to get a final concentration of $10 \mu \mathrm{g} / \mathrm{ml}$.

\section{Method validation}

ICH Q2A, ICH Q2B guidelines were followed for the validation of the method to evaluate the parameters: Linearity, accuracy, precision, the limit of detection (LOD) and limit of quantification (LOQ), specificity and robustness.

\section{RESULTS AND DISCUSSION}

\section{Optimization of spectrophotometric conditions}

Ideal solvent for the method was selected after several experimental trials. Solvents like water, methanol, ethanol, isopropanol and acetonitrile used initially. Because of better solubility and reproducible readings of absorbance maxima, acetonitrile was used for the method development. The absorbance maxima for the method was carefully chosen after obtaining the absorbance spectra of standard and sample (formulation) solution of TEF.

\section{Linearity}

The calibration curve (fig. 2) was plotted between absorbance versus concentration. The linearity of TEF was constructed by scanning six 
standard solutions in the concentration range of 5-10 $\mu \mathrm{g} / \mathrm{ml}$. The line equation $\mathrm{y}=0.0858 \mathrm{x}-0.0223$ and $\mathrm{r}^{2}$ value of 0.9996 demonstrated the good linearity of the method. The calibration curve of linearity and overlay spectra of TEF is depicted in fig. 2 and 3, respectively.

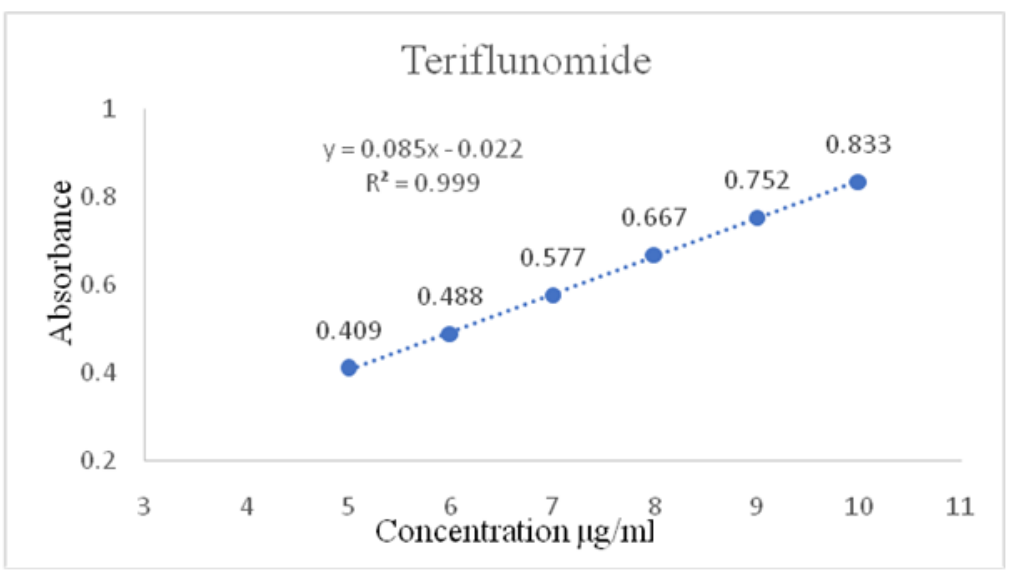

Fig. 2: Calibration curve of TEF



Fig. 3: Overlay spectra of TEF

Table 1: Accuracy study of TEF

\begin{tabular}{|c|c|c|c|c|}
\hline Level of recovery & Quantity of formulation $(\mu \mathrm{g} / \mathrm{ml})$ & Quantity of pure drug added $(\mu \mathrm{g} / \mathrm{ml})$ & \% recovery & Mean \\
\hline \multirow[t]{3}{*}{80} & 5 & 4 & 98.7 & 99.3 \\
\hline & 5 & 4 & 100 & \\
\hline & 5 & 4 & 99.25 & \\
\hline \multirow[t]{3}{*}{100} & 5 & 10 & 98.5 & 100.4 \\
\hline & 5 & 10 & 102.2 & \\
\hline & 5 & 10 & 100.3 & \\
\hline \multirow[t]{3}{*}{120} & 5 & 11 & 100.74 & 98.6 \\
\hline & 5 & 11 & 98.01 & \\
\hline & 5 & 11 & 99 & \\
\hline
\end{tabular}

\section{Accuracy}

Accuracy was assessed in terms of percentage recovery, by spiking the band of formulation with $80 \%, 100 \%, 120 \%$ of pure drug and then finding out the amount of the drug recovered. The mean percentage recovery was found to be $99.4 \%$, as depicted in table 1 .

\section{Precision}

Intraday and interday precision of the method was assessed by measuring the absorbance of highest concentration six times in the same day and the consecutive day respectively. Precision was reported in terms of \%RSD. The \% RSD values were found to be less than $2 \%$ as depicted in table 2 , indicating high precision of the developed method.

\section{Limit of detection and limit of quantitation}

LOD and LOQ were assessed with the aid of standard deviation $(\sigma)$ and slope (s) from the calibration curve $(\mathrm{n}=3)$, by using the equation $\mathrm{LOD}=3.3 \mathrm{\sigma} / \mathrm{s}$ and LOQ $=10 \mathrm{\sigma} / \mathrm{s}$. LOD and LOQ of TEF were found to be $0.38 \mu \mathrm{g} / \mathrm{ml}$ and $1.1 \mu \mathrm{g} / \mathrm{ml}$, respectively indicating the good sensitivity of the method towards the analyte. The LOD and LOQ is depicted in table 3. 


\section{Specificity}

The specificity of the method was assessed by comparing the UV absorption spectra and absorbance maxima of standard TEF with the formulation as depicted in fig. 4 . The spectra of both standard and formulation showed absorbance maxima value indicating the good specificity of the method.

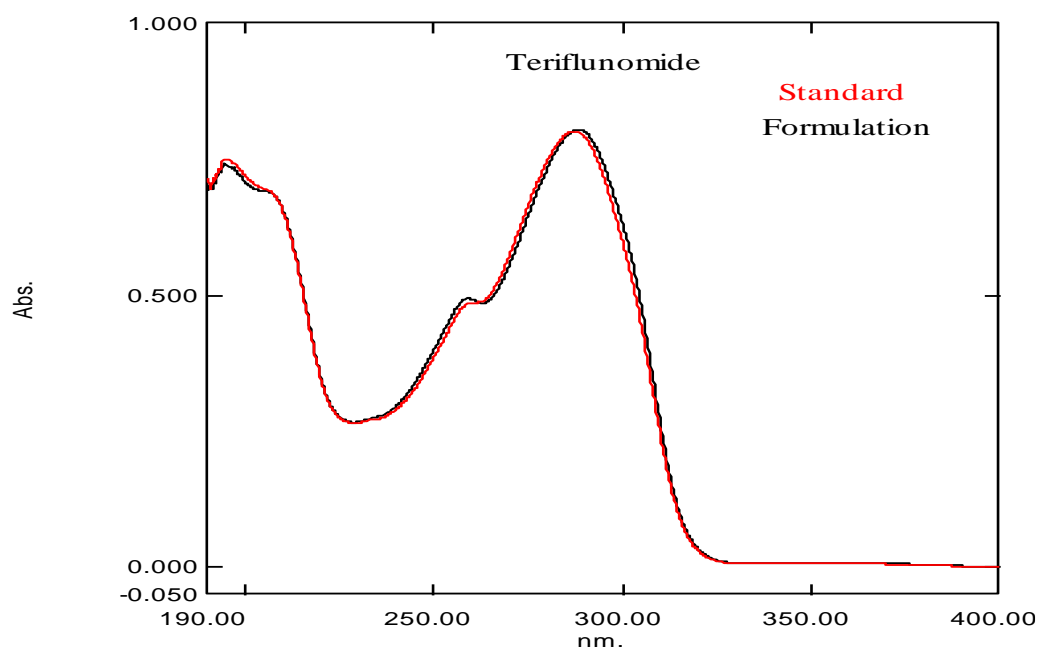

Fig. 4: Overlay spectra of TEF

\section{Robustness}

The robustness was assessed by making small but thoughtfu changes in the method parameters such as; scanning wavelength and finding out its effect on the absorbance by calculating \%RSD. The \% RSD was found to be within $2 \%$, which indicates the reliability of the method. The robustness of the method is depicted in table 3 .

Table 2: Overall validation report of the method

\begin{tabular}{lll}
\hline Parameters & Values \\
\hline Linearity & Inter-day $(\mathrm{n}=6)$ & $5-10 \mu \mathrm{g} / \mathrm{ml}$ \\
Precision & Intra-day $(\mathrm{n}=6)$ & $\% \mathrm{RSD}=0.508521$ \\
& & $\% \mathrm{RSD}=0.558522$ \\
Accuracy $(80 \%, 100 \%, 120 \%)$ & $99.4 \%(\mathrm{Mean})$ \\
LOD & & $0.38 \mu \mathrm{g} / \mathrm{ml}$ \\
LOQ & $1.1 \mu \mathrm{g} / \mathrm{ml}$ \\
Robustness $(\mathrm{n}=6)$ & $\% \mathrm{RSD}=0.6781$ \\
\hline
\end{tabular}

\section{Analysis of formulation}

The $\%$ of the drug found in the formulation from the currently developed method was found to be $99.4 \%$. The absorbance spectra obtained from the formulation (fig. 5) exhibited no interference of the excipients. The close agreement of the percentage of drug found with label claim depicted application of this method for the routine analysis of TEF present in its formulation, as depicted in table 3.

Table 3: Analysis of formulation

\begin{tabular}{llll}
\hline Formulation & Drug & Label Claim (mg) & Quantity found (mg) \\
\hline Denopsy 14 & Teriflunomide & Each tablet consists of 14 mg of TEF & \% label claim \\
\hline
\end{tabular}

\section{CONCLUSION}

A novel simple, rapid and precise UV-Visible spectrophotometric method has been developed for the determination of Teriflunomide in marketed formulation. This validated method can be used by quality control laboratories for the routine quantitative analysis of tablets consisting of Teriflunomide as the additives used in the formulation do not interfere with the analysis. Non-requirement of skilled personnel to operate the instruments involved is an added advantage of this method.

\section{ACKNOWLEDGMENT}

The authors extend their gratitude to Principal, JSS College of Pharmacy Mysuru for providing the necessary resources for the work.

\section{AUTHORS CONTRIBUTIONS}

All the author have contributed equally

\section{CONFLICT OF INTERESTS}

Declare none

\section{REFERENCES}

1. J Marriott J, W O'Connor P. Emerging therapies in relapsingremitting multiple sclerosis. Rev Recent Clin Trials 2010;5:179. 88.

2. Bruneau JM, Spinella Jaegle S, Fudali C, Woodward K, Robson PA, SautEs C, et al. Purification of human dihydro-orotate dehydrogenase and its inhibition by A77 1726, the active metabolite of leflunomide. Biochem J 1998;336:299-303. 
3. O'connor PW, Li D, Freedman MS, Bar-Or A, Rice GP, Confavreux C, et al. A phase II study of the safety and efficacy of teriflunomide in multiple sclerosis with relapses. Neurology 2006;66:894-900

4. Klineova S, Krieger S. Emerging therapies in multiple sclerosis, Handbook of Relapsing-Remitting Multiple Sclerosis; 2017. p. 99-113.

5. Sobhani K, Garrett DA, Liu DP, Rainey PM. A rapid and simple high-performance liquid chromatography assay for the leflunomide metabolite, teriflunomide (A77 1726), in renal transplant recipients. Am J Clin Pathol 2010;133:454-7.

6. Schmidt A, Schwind B, Gillich M, Brune K, Hinz B. Simultaneous determination of leflunomide and its active metabolite, A77 1726, in human plasma by high-performance liquid chromatography. Biomed Chromatogr 2003;17:276-81.

7. Nadella NP, Ratnakaram VN, Srinivasu N. Quality-by-designbased development and validation of a stability-indicating UPLC method for quantification of teriflunomide in the presence of degradation products and its application to in vitro dissolution. J Liq Chromatogr R T 2017;40:517-27.

8. Mehta B, Prajapat P, Gohil Y. Development and validation of stability indicating RP-HPLC method for estimation of teriflunomide in the active pharmaceutical ingredient. Pharm Innovation 2017;6:440-9.

9. Parekh JM, Vaghela RN, Sutariya DK, Sanyal M, Yadav M, Shrivastav PS. Chromatographic separation and sensitive determination of teriflunomide, an active metabolite of leflunomide in human plasma by liquid chromatographytandem mass spectrometry. J Chromatogr B 2010;878:2217-25.

10. Rakhila H, Rozek T, Hopkins A, Proudman S, Cleland L, James M, et al. Quantitation of total and free teriflunomide (A77 1726) in human plasma by LC-MS/MS. J Pharm Biomed Anal 2011; 55:325-31.

11. Rule GS, Rockwood AL, Johnson Davis KL. LC-MS/MS method for determination of teriflunomide, over a 40,000-fold dynamic range using overlapping calibrators. Ther Drug Monit 2015;37:472-8.

12. Suneetha A, Raja RK. Comparison of LC-UV and LC-MS methods for simultaneous determination of teriflunomide, dimethyl fumarate and fampridine in human plasma: application to rat pharmacokinetic study. Biomed Chromatogr 2016;30:1371-7.

13. ICH Q2A Text on Validation of analytical procedures, International Conference on Harmonization tripartite guidelines; 1994.

14. ICH Q2B Text on validation of analytical procedures: Methodology International Conference on Harmonization; 1996. 